\title{
Regulatory Effects of Endogenous Interleukin-1 Receptor Antagonist Protein in Immunoglobulin G Immune Complex-induced Lung Injury
}

\author{
Thomas P. Shanley, James L. Peters, Michael L. Jones, Stephen W. Chensue, Steven L. Kunkel, and Peter A. Ward \\ Department of Pathology, University of Michigan Medical School, Ann Arbor, Michigan 48109
}

\begin{abstract}
IL-1 receptor antagonist (IL-1Ra) has regulatory effects on IL-1 activity both in vitro and in vivo. In the IgG immune complex model of lung injury in rats, exogenously administered human IL-1Ra suppressed neutrophil recruitment and ensuing lung injury. In this study, we sought to determine if endogenous rat IL-1Ra might regulate this lunginflammatory response. By Northern blot analysis of lung mRNA and Western analysis of bronchoalveolar lavage (BAL) fluids, rat IL-1Ra expression was found to increase during development of inflammation in IgG immune complex-mediated alveolitis. By immunostaining, alveolar macrophages and recruited neutrophils were the apparent sources of IL-1Ra. In vivo blocking of endogenous IL-1Ra resulted in a 53\% increase in lung vascular permeability and a $180 \%$ increase in BAL fluid neutrophils. In companion studies, a significant increase in BAL IL-1 $\beta$ was found, whereas no significant change in TNF- $\alpha$ activity was observed. Whereas the in vivo regulatory effects of IL-1Ra appear to be limited to IL-1 $\beta$, IL-10 regulates both IL-1 $\beta$ and TNF- $\alpha$ in this model, reflected by a $48 \%$ increase in BAL IL-1 $\beta$ in rats treated with anti-IL-10. These findings suggest that IL-1Ra is an intrinsic regulator of inflammatory injury after deposition of IgG immune complexes and that it regulates production of IL-1 $\beta$. (J. Clin. Invest. 1996. 97: 963-970.) Key words: IL-1Ra • lung injury • IL-1 $\beta$ - TNF- $\alpha$ - immune complexes • neutrophils
\end{abstract}

\section{Introduction}

IL-1 is an important proinflammatory cytokine derived from monocytes, macrophages, and other cells and has several biological effects (for reviews see references 1 and 2). There exist $\alpha$ and $\beta$ forms of IL-1, which, despite sharing only $\sim 29 \%$ homology, display similar effects, including induction of adhesion molecule expression on endothelial cells (3), neutrophil recruitment in vivo (4), and production of fever, hypotension, and peripheral neutrophilia as well as many other biological effects $(1,2,5)$. Based on these properties, IL-1 has been impli-

Address correspondence and reprint requests to Peter A. Ward, M.D., Department of Pathology, University of Michigan Medical School, 1301 Catherine Street, Box 0602, Ann Arbor, MI 48109-0602. Phone: 313-747-2921; FAX: 313-763-4782.

Received for publication 4 May 1995 and accepted in revised form 1 December 1995.

J. Clin. Invest.

(C) The American Society for Clinical Investigation, Inc.

0021-9738/96/02/0963/08 \$2.00

Volume 97, Number 4, February 1996, 963-970 cated in a range of inflammatory diseases. The pleiotropic properties of IL-1 suggest that it is probably subject to stringent in vivo regulation.

There are several potential mechanisms for intrinsic regulation of IL-1 (6), including blocking of IL-1 gene transcription, binding of secreted IL-1 by soluble IL-1 receptors (7), IL-1 receptor antagonism, and interference with IL-1-induced signal transduction at a postreceptor level. IL-1 receptor blockade was originally suggested by the report of an IL-1 competitive inhibitor that bound to the IL-1 receptor without producing the agonist effects (8) and supported by the identification of a cDNA for and functional expression of this inhibitor $(9,10)$. Production of the IL-1 receptor antagonist protein (IL-1Ra) ${ }^{1}$ occurred after adherence of human monocytes to solid-phase IgG (10) or by stimulating human myelomonocytic cells with both PMA and GM-CSF (11). IL-1Ra synthesis was induced by phagocytic cell triggers such as immune complexes, LPS, and PMA (12), suggesting that IL-1Ra has natural regulatory functions.

Whereas expression of IL-1Ra has been studied under a variety of in vitro conditions, there are no reports that elucidate the role of endogenous IL-1Ra in in vivo models of acute lung injury. Since intrapulmonary deposition of $\mathrm{IgG}$ immune complexes leads to production of IL-1 (13), and monocytes grown on adherent immune complexes produce IL-1Ra (10, 14), we sought to determine if IL-1Ra was produced during the development of acute lung injury after intrapulmonary deposition of IgG immune complexes. mRNA for IL-1Ra in lung tissue and IL-1Ra protein in bronchoalveolar lavage (BAL) fluids were detected during the course of this experimental inflammatory reaction. Immunofluorescent staining for IL$1 \mathrm{Ra}$ identified both alveolar macrophages and neutrophils as likely sources of IL-1Ra. Considering that IL-1Ra might function as an endogenous regulator of inflammation, intravenous administration of anti-IL-1Ra at the commencement of lung injury was performed and resulted in augmentation of injury, as reflected by increased lung permeability and enhanced BAL neutrophil counts. Additionally, under these same conditions, an increase in the level of IL- $1 \beta$ in BAL fluids was detected without a concurrent increase in TNF- $\alpha$ activity. This pattern differs from the findings in the same experimental model after neutralization of intrinsic IL-10, which led to increases in both IL-1 $\beta$ (presented below) and TNF- $\alpha$ in BAL fluids (15). Taken together, the current data support the concept that IL-1Ra is an important endogenous regulatory protein of IL-1 $\beta$ during the development of acute lung injury. These studies also suggest that regulation of IL-1 $\beta$ expression by endogenous IL-1Ra is selective and does not extend to regulation of TNF- $\alpha$.

1. Abbreviations used in this paper: BAL, bronchoalveolar lavage; IL-1Ra, IL-1 receptor antagonist protein. 


\section{Methods}

Reagents. All reagents were purchased from the Sigma Chemical Corp. (St. Louis, MO) except where otherwise noted.

Antibody. Rabbits were immunized with recombinant murine IL$1 \mathrm{Ra}$ in CFA. Polyclonal rabbit antibody was titered for reactivity to human IL-1Ra by indirect ELISA. Briefly, a 96-well ELISA plate (Immulon 4, Chantilly, VA) was coated with soluble recombinant human IL-1Ra $(1 \mu \mathrm{g} / \mathrm{ml})$ overnight at $4^{\circ} \mathrm{C}$. The plate was blocked with $2 \% \mathrm{BSA}$ in PBS, $\mathrm{pH} 7.4$, for $1 \mathrm{~h}$ before addition of serial dilutions of rabbit anti-murine IL-1Ra serum. The plate was washed, and $100 \mu \mathrm{l} /$ well horseradish-peroxidase-conjugated goat anti-rabbit antibody (1:3,000 dilution; Bio-Rad Laboratories, Richmond, CA) was incubated with samples. The reaction was developed with $o$-phenylenediamine dihydrochloride substrate and was stopped with $3 \mathrm{M} \mathrm{H}_{2} \mathrm{SO}_{4}$. Titers were determined by measuring absorbance at $490 \mathrm{~nm}$. Where indicated, rats undergoing $\mathrm{IgG}$ immune complex-induced lung injury received $0.5 \mathrm{ml}$ antiserum to $\mathrm{IL}-1 \mathrm{Ra}$ (titer $\geq 10^{-5}$ ) intravenously upon initiation of injury as described below. A companion set of rats received intravenously $0.5 \mathrm{ml}$ serum obtained from rabbits before immunization with IL-1Ra (preimmune serum).

For Western blot analysis and immunofluorescent staining (see below), goat anti-murine IL-1Ra antibody provided by S.W. Chensue was used as the primary antibody.

Model of IgG immune complex-induced alveolitis. For all studies, adult male 275-300-g (specific pathogen-free) Long-Evans rats were used. Rabbit polyclonal IgG rich in antibody to BSA (anti-BSA) was used in the IgG immune complex model of lung injury. Intraperitoneal ketamine was administered for sedation and anesthesia. $2.5 \mathrm{mg}$ rabbit IgG anti-BSA in a volume of $300 \mu \mathrm{l}$ PBS was instilled via an intratracheal catheter during inspiration. Immediately thereafter, 10 mg BSA together with trace amounts of ${ }^{125}$ I-BSA (as quantitative marker of permeability) were injected intravenously, as described elsewhere (16). Rats were killed $4 \mathrm{~h}$ later, the pulmonary circulation was flushed with saline, the lungs were surgically dissected, and the amount of radioactivity ( ${ }^{125} \mathrm{I}$-BSA) was determined by scintillation counting to quantitate lung injury by increases in vascular permeability. Negative control animals received anti-BSA intratracheally without BSA administration by the intravenous route. For calculations of the permeability index, the amount of radioactivity ( ${ }^{125} \mathrm{I}-\mathrm{BSA}$ ) remaining in the saline-perfused lungs was compared with the amount of radioactivity present in $1.0 \mathrm{ml}$ blood obtained from the inferior vena cava at the time of death.

Cloning of rat IL-1Ra and detection of $m R N A$ by Northern blot analysis. Full-length cDNA for rat IL-1Ra was PCR cloned by reverse transcription of mRNA isolated from IgG immune complexinjured lungs. The PCR reaction was primed using the following oligonucleotides: 5' primer: 5'-ATG GAA ATC TGC AGG GCA CCT-3'; 3' primer: 5'-CTA TTG GTC TTC CTG GAA GTA-3'. The cDNA product was ligated into a PCR $^{\mathrm{TM}}$ cloning vector (Invitrogen, San Diego, CA), sequenced, and confirmed to be secretory rat IL-1Ra cDNA by comparison with the published sequence (17). These primers were predicted to amplify the cDNA encoding the secretory form of rat IL-1Ra; however, it may also hybridize to the as yet uncharacterized intracellular form of rat IL-1Ra. After IgG immune complex deposition, rats were killed at 2-h intervals from 0 to $8 \mathrm{~h}$. Whole lungs were dissected and frozen in liquid nitrogen for Northern blot analysis of IL-1Ra mRNA. RNA was extracted using a guanidiniumisothiocyanate method as described previously (18). $12 \mu \mathrm{g}$ RNA was fractionated electrophoretically in a $1 \%$ formaldehyde gel and transferred to a nylon blot (Zetabind; Cuno, Inc., Meriden, CT). The cDNA for rat IL-1Ra was $\left[{ }^{32} \mathrm{P}\right] \mathrm{dCTP}$ radiolabeled (DuPont-NEN, Boston, MA) by PCR amplification to generate the cDNA probe. Hybridization to mRNA was performed at $65^{\circ} \mathrm{C}$ for $18 \mathrm{~h}$, and the autoradiogram was developed on X-Omat film (Eastman Kodak, Inc., Rochester, NY). Densitometry was performed using a densitometer (Fotodyne, Inc., New Berlin, WI) with AMBIS software (San Diego, CA). Equal loading of samples was confirmed by methylene blue staining of $18 \mathrm{~S}$ and $28 \mathrm{~S}$ rRNA bands and probing with $\left[{ }^{32} \mathrm{P}\right] \mathrm{dCTP}-$ radiolabeled $\beta$-actin.

Western blot analysis for IL-1Ra. At the times indicated $(0-8 \mathrm{~h})$, $8 \mathrm{ml}$ PBS was instilled three times and withdrawn from the lungs via an intratracheal cannula. BAL fluids were subjected to SDS/PAGE $(15 \%)$ according to the method of Laemmli (19). At each time point, $40 \mu \mathrm{g}$ of total protein (BAL fluid volume between 16 and $20 \mu \mathrm{l}$ ) was loaded in each lane under reducing conditions. The separated proteins were transblotted to nitrocellulose $(0.45 \mu \mathrm{m}$; Bio-Rad Laboratories) for $2 \mathrm{~h}$ at $12 \mathrm{~V}$. After transfer, the membrane was blocked with $20 \mathrm{mM}$ Tris- $\mathrm{HCl}$, pH 7.5; $500 \mathrm{mM} \mathrm{NaCl} ; 0.05 \%$ Tween 20 (T-TBS) ( $\mathrm{vol} / \mathrm{vol}$ ) containing $3 \% \mathrm{BSA}$ for $2 \mathrm{~h}$ at room temperature. The blot was next incubated for $1 \mathrm{~h}$ with the primary antibody (goat antimurine IL-1Ra antiserum, 1:500 dilution). After washing, secondary antibody (rabbit anti-goat IgG alkaline phosphatase-conjugated antibody; Bio-Rad Laboratories) was added at a final dilution of 1:3,000 in T-TBS and incubated for $30 \mathrm{~min}$. After washing, the membrane was developed by the addition of alkaline phosphatase substrate solution (5-bromo-4-chloro-3-indoyl phosphate and nitroblue tetrazolium in $10 \mathrm{mM}$ Tris, $\mathrm{pH}$ 9.5). Rainbow molecular weight markers (Amersham Corp., Arlington Heights, IL) were used to estimate the size of the immunoreactive bands (2,350-46,000 D). Recombinant murine IL-1Ra kindly provided by Dr. M. Bienkowski (Cell Biology Unit, Upjohn Co., Kalamazoo, MI) was used as control.

$B A L$ fluid analysis: neutrophils, $I L-1 \beta$, and TNF- $\alpha$ quantitation. The BAL fluids were collected as described above, and total white cell counts were determined using a Coulter counter (Coulter Electronics, Hialeah, FL). Cell differentials were determined using cytospin centrifugation (700 $g$ for $7 \mathrm{~min}$ ) on BAL fluids. Specimens were fixed and stained with Diff-Quik products (Baxter Healthcare Corp., Miami, FL) for determination of percentage of neutrophils and macrophages/monocytes. The total numbers of neutrophils for each BAL sample were then determined according to the volume of BAL recovered.

Remaining BAL samples were centrifuged at $1,500 \mathrm{~g}$ for $10 \mathrm{~min}$, and the supernatant fluids were evaluated by ELISA for IL-1 $\beta$ using a murine IL-1 $\beta$ ELISA kit provided by BioSource Intl. (Camarillo, CA) that has demonstrated cross-reactivity with rat IL-1 $\beta$. The minimal detectable concentration of IL- $1 \beta$ is $<7 \mathrm{pg} / \mathrm{ml}$. The anti-IL-1Ra serum at a 1:200 dilution did not interfere with IL-1 $\beta$ standard curve determination.

Finally, TNF- $\alpha$ activity in BAL samples was determined using a standard LM cell cytotoxicity assay as previously reported (20).

Identification of cell sources of IL-1Ra. BAL fluids obtained from rats undergoing IgG immune complex-induced lung injury were subjected to centrifugation at $1,500 \mathrm{~g}$ for $10 \mathrm{~min}$. Hypotonic lysis of red blood cells was performed, and the remaining cells were resuspended in $1 \%$ BSA in PBS at a concentration of 500,000 cells $/ \mathrm{ml}$. Samples for immunofluorescent staining were obtained by spinning $100 \mu \mathrm{l}$ of these cell suspensions in a centrifuge (Cytospin Shandon Scientific Ltd., Shandon, UK; $700 \mathrm{~g}, 7 \mathrm{~min}$ ). Cytospin specimens were first fixed with $100 \%$ methanol and stored in $-20^{\circ} \mathrm{C}$ before staining. For staining, specimens were fixed with acetone and allowed to air dry. Samples were then incubated at $4^{\circ} \mathrm{C}$ with the primary antibodies, either anti-murine IL-1Ra antiserum (1:500 dilution, positive control), or preimmune rabbit serum (1:500 dilution, negative control). After overnight incubation, the slides were washed in PBS $(5 \mathrm{~min})$ and then treated with a rhodamine-conjugated, anti-rabbit IgG secondary antibody (Sigma Immunochemicals) at room temperature for $45 \mathrm{~min}$. Slides were washed in PBS and fixed with mounting solution (Fluoromount-G; Southern Biotechnology Associates, Inc., Birmingham, $\mathrm{AL})$ for evaluation by fluorescence microscopy.

Statistical analysis. All values were expressed as mean \pm SEM. For all data points in the studies described, $n \geq 5$. Data sets were examined with one- and two-way ANOVA to determine statistical significance at $P<0.05$. Statistical significance between individual group means was then determined with Tukey's procedure. For calculation of percentage change in permeability indices, mean negative 
control values were first subtracted from values in positive control groups and in each treatment group.

\section{Result}

IL-1Ra $m R N A$ time course in IgG immune complex-induced alveolitis. Expression of mRNA for IL-1Ra in lung extracts from animals undergoing IgG immune complex-induced lung injury was determined as a function of time $(0-8 \mathrm{~h})$ after induction of the lung-inflammatory reaction. RNA was analyzed by Northern blots that were probed with ${ }^{32} \mathrm{P}$-labeled cDNA for rat IL-1Ra. The results in which the mean relative optical density as a function of time was determined are shown in Fig. $1 A$. Equal gel loading of RNA was suggested by methylene blue staining of $18 \mathrm{~S}$ and $28 \mathrm{~S}$ bands (Fig. $1 \mathrm{C}$ ) and confirmed by determination of $\beta$-actin levels (Fig. $1 D$ ). Whereas very little mRNA was found at $0 \mathrm{~h}$, there was a progressive increase in IL-1Ra mRNA between 2 and 4 h, with peak mRNA expression occurring at $6 \mathrm{~h}$ (Fig. $1 B)$.

IL-1Ra content in BAL fluids during IgG immune complex-induced lung injury. IL-1Ra content in BAL fluids of lungs injured by IgG immune complex deposition was confirmed by Western blot analysis. In rat lung, IL-1Ra appeared to be constitutively expressed, since animals killed at the initiation of injury $(0 \mathrm{~h})$ had detectable IL-1Ra (Fig. 2). The predominant immunoreactive material appeared at $18 \mathrm{kD}$, consistent with the predicted molecular weight of rat IL-1Ra. In addition, murine recombinant IL-1Ra was run simultaneously as standard and demonstrated immunoreactivity at the same molecular weight (Fig. 2). Though only semiquantitative, peak expression of IL-1Ra in BAL fluids appeared to occur at $6 \mathrm{~h}$, followed by a decline at $8 \mathrm{~h}$ (Fig. 2).

The band at $28 \mathrm{kD}$ is a nonspecific one unrelated to rat IL$1 \mathrm{Ra}$. This band most likely reflects reactivity between a fragment of rabbit $\operatorname{IgG}$ and the secondary antibody based on the observations that this band appears on Western blots developed with antibody to IL-1Ra absorbed with IL-1Ra, whereas the reactivity with the bands at $18 \mathrm{kD}$ is lost (data not shown). Furthermore, BAL fluids from rats not given rabbit anti-BSA intratracheally do not contain a band at $28 \mathrm{kD}$ (data not shown).

Source of IL-1Ra production during IgG immune complexinduced lung injury. Fluorescent microscopy of cytospin cell preparations obtained at time $0 \mathrm{~h}$ suggested little, if any, presence of IL-1Ra in alveolar macrophages. A substantial number of both macrophages and neutrophils obtained $4 \mathrm{~h}$ after the initiation of lung injury in BAL fluids demonstrated cytoplasmic staining for IL-1Ra (Fig. 3, $A$ and $B$ ). No staining of cells was observed in the 4-h cytospin preparations when preimmune rabbit serum was used as the primary antibody (Fig. 3 $C)$. Because of the lack of fluorescent signaling, the automated camera lengthened the photographic exposure time for the sections stained with preimmune serum so that the background intensity was higher. However, it is clear that no cells stained positively with preimmune sera. These results demonstrate that, after induction of lung injury by IgG immune complex deposition, both macrophages and neutrophils may be sources of IL-1Ra production. Production of IL-1Ra by other potential sources such as epithelial cells was not assessed in these studies.

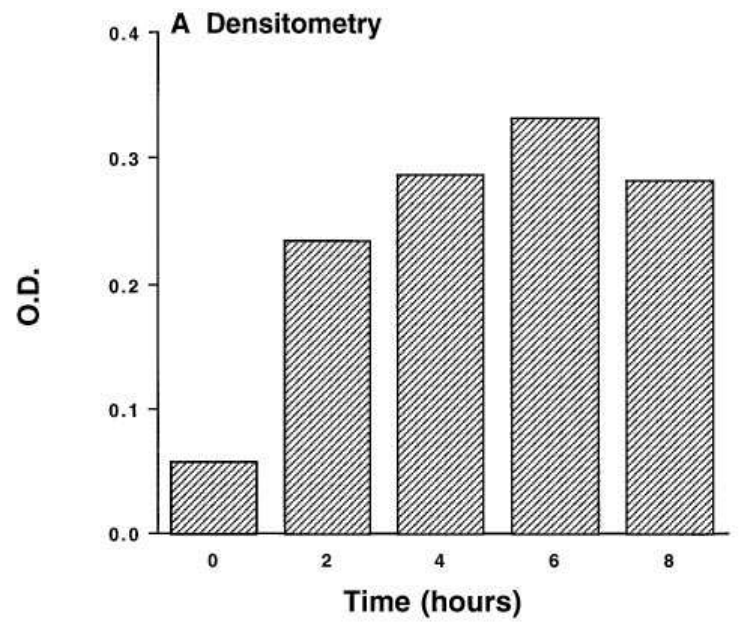

B Northern Analysis

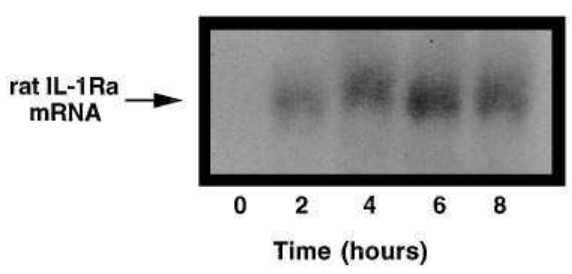

C RNA Loading

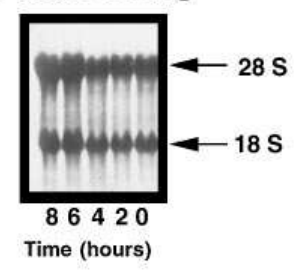

D B-actin Labeling

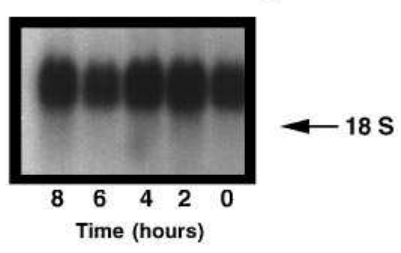

Figure 1. Time course in appearance of IL-1Ra mRNA from lung extracts obtained during intrapulmonary deposition of IgG immune complexes $(A$ and $B)$. Quantitation was by densitometry of Northern blots. A representative blot is shown. Equal loading was confirmed by methylene blue staining of $18 \mathrm{~S}$ and $28 \mathrm{~S}$ rRNA bands $(C)$ and $\beta$-actin probing $(D)$ as shown. 


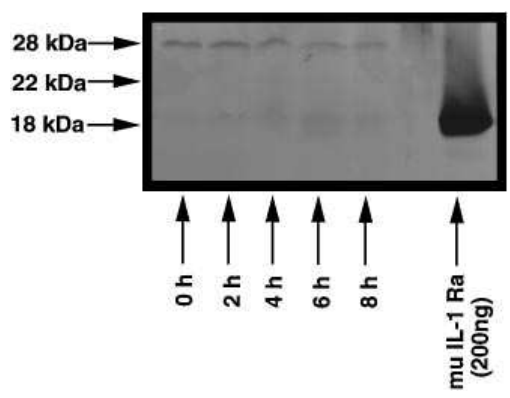

Figure 2. Immunoreactive IL-1Ra protein, as determined by Western blot analysis, in BAL fluids during intrapulmonary deposition of $\mathrm{IgG}$ immune complexes. While minor constitutive expression is seen $(0 \mathrm{~h})$, peak expression is observed at $6 \mathrm{~h} .40 \mu \mathrm{g}$ total protein from BAL samples was loaded in each lane, and the blot was developed with goat anti-murine IL-1Ra antiserum (1:500 dilution). The control lane contains $200 \mathrm{ng}$ recombinant murine IL-1Ra. The band at $28 \mathrm{kD}$ is unrelated to rat IL-1Ra (see Results)

Augmentation of IgG immune complex-mediated lung injury by anti-IL-1Ra. Lung injury was induced (as described above), and the parameters of injury were determined at $4 \mathrm{~h}$. The mean permeability values in the negative (anti-BSA alone) and positive controls (anti-BSA+BSA) were $0.18 \pm 0.02$ and $0.73 \pm 0.05$, respectively (Fig. 4). When compared with the anti-BSA + BSA group, the intravenous administration of $0.5 \mathrm{ml}$ of preimmune serum to rats undergoing IgG immune complex-induced lung injury (Fig. 4; anti-BSA+ $B S A+$ preimmune) did not result in a statistically significant change in permeability $(0.64 \pm 0.07)$. However, in companion animals treated at time $0 \mathrm{~h}$ with $0.5 \mathrm{ml}$ anti-IL-1Ra antiserum (Fig. 4; anti-BSA+BSA+anti-IL-1Ra), a 53\% increase in lung permeability index $(1.02 \pm 0.12 ; P=0.02)$ was evident at the time of death $(4 \mathrm{~h})$.

The effect of anti-IL-1Ra treatment on neutrophils retrieved in BAL fluids was assessed. Total BAL neutrophil numbers were determined and expressed as BAL neutrophil counts $\times 10^{3}$ (Fig. 5). The mean volume of BAL fluids recovered from all study animals was $6.4 \pm 0.3 \mathrm{ml}$. IgG immune complex-induced injury (anti-BSA+BSA) was associated with a fourfold increase in BAL neutrophils compared with negative controls (anti-BSA alone). The mean neutrophil number increased from $387 \pm 77 \times 10^{3}$ in animals receiving only anti-BSA intratracheally (Fig. 5; anti-BSA alone) to $2,331 \pm 304 \times 10^{3}$ in positive control animals otherwise untreated (Fig. 5; anti-BSA $+B S A$ ). As shown in Fig. 5, administration of preimmune serum to a companion set of anti-BSA + BSA rats did not significantly change BAL neutrophil counts $\left(1,740 \pm 228 \times 10^{3}\right.$; anti$B S A+B S A+$ preimmune), whereas treatment of rats with 0.5 $\mathrm{ml}$ anti-IL-1Ra antiserum resulted in a $180 \%$ increase in BAL neutrophils $\left(6,575 \pm 847 \times 10^{3} ; P<0.001 ;\right.$ anti-BSA $+B S A+$ anti-IL-1Ra).

Effect of anti-IL-1Ra on IL-1 $\beta$ content in BAL fluids. Levels of IL-1 $\beta$ in BAL fluids obtained $4 \mathrm{~h}$ after initiation of lung inflammatory reactions were determined by ELISA. Animals that received anti-BSA alone had no IL- $1 \beta$ detectable in BAL fluids by this assay. Intrapulmonary deposition of $\mathrm{IgG}$ immune complexes resulted in a significant increase in IL-1 $\beta(24.6 \pm 8$
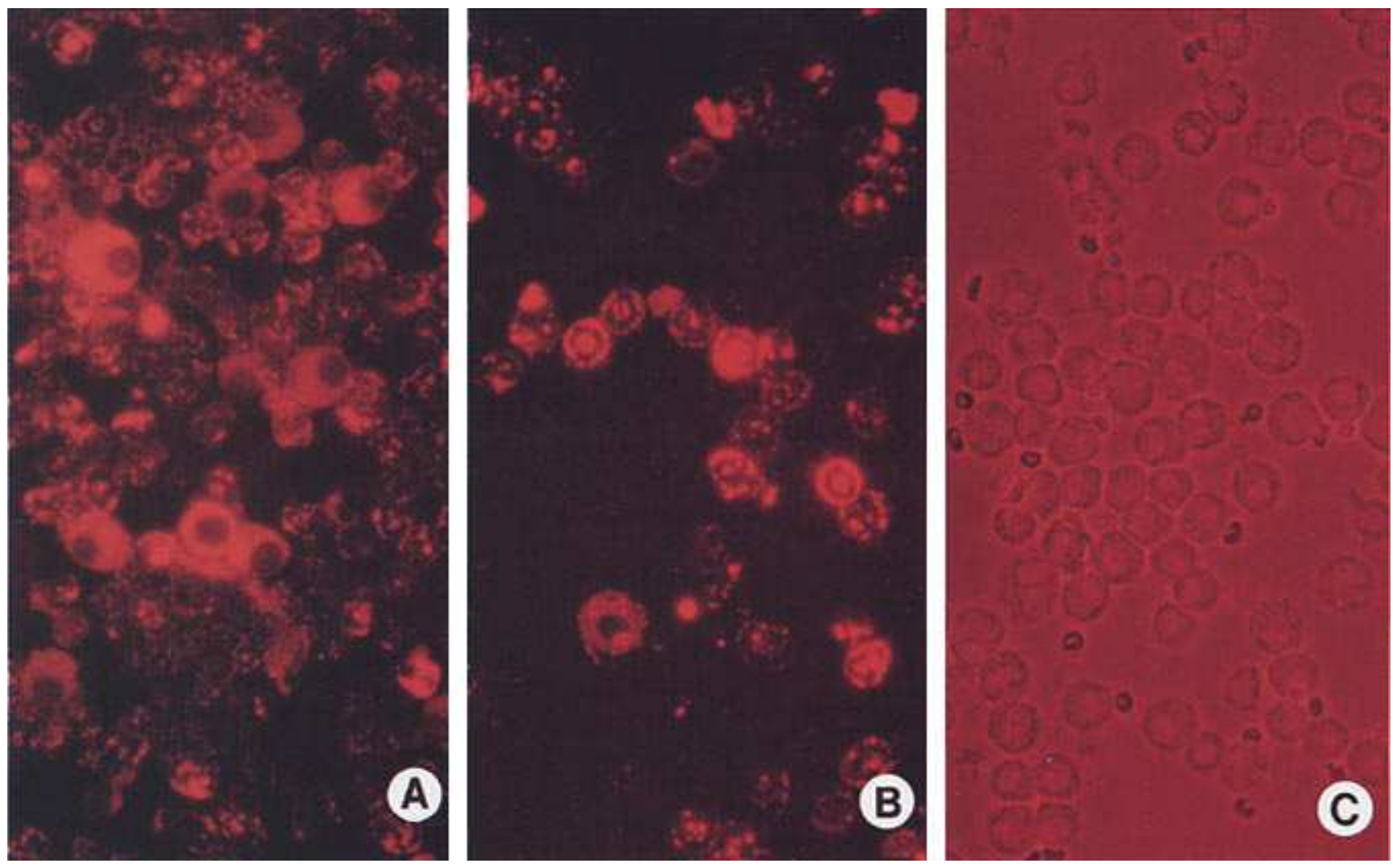

Figure 3. Immunofluorescent (rhodamine) staining for IL-1Ra in cytospin samples from BAL fluids after induction of IgG immune complex alveolitis. By $4 \mathrm{~h}$, a substantial number of both macrophages $(A)$ and neutrophils $(B)$ stain positively for IL-1Ra. No staining is observed using preimmune rabbit serum as the primary antibody $(C)$. Note that the exposure time in $C$ was prolonged compared with those in $A$ and $B$. As such, cells have staining that is no greater than background staining. All frames, $\times 40$. 


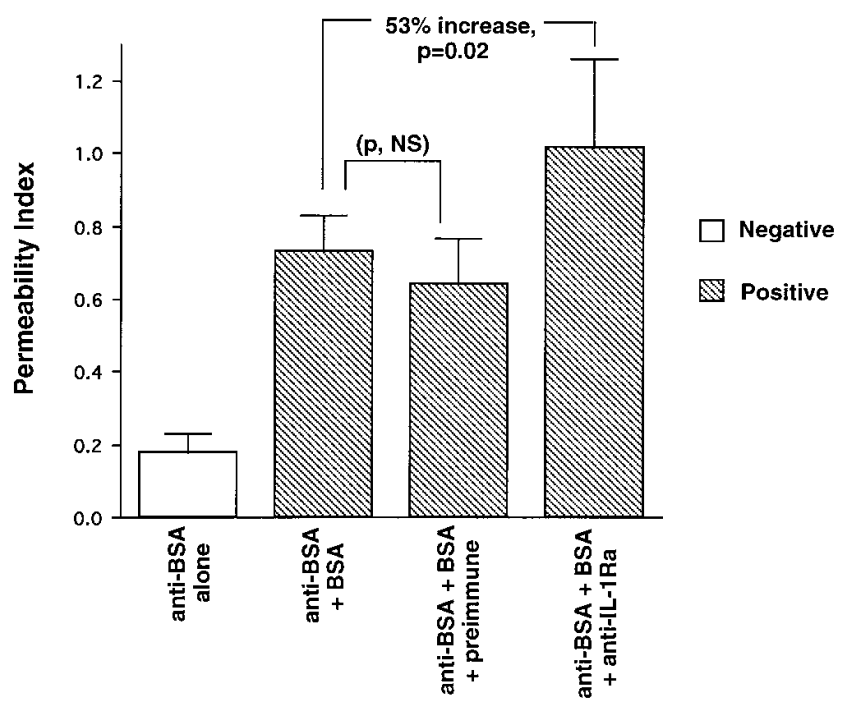

Figure 4. Augmentation in lung injury (as defined by leakage of ${ }^{125} \mathrm{I}$ albumin) $4 \mathrm{~h}$ after intrapulmonary deposition of IgG immune complexes in rats treated with blocking antibody to IL-1Ra. Negative control animals designated anti-BSA alone (open bars) received antiBSA intratracheally, with omission of the intravenous dose of BSA. The remaining groups underwent lung injury induced by $\mathrm{IgG}$ immune complex deposition (stippled bars) by intratracheal administration of anti-BSA and intravenous administration of BSA as described in Methods. Subsequently, rats received either preimmune serum (anti$B S A+B S A+$ preimmune) or anti-IL-1Ra serum (anti-BSA + BSA + anti-IL-1Ra) intravenously at time 0 , or were otherwise untreated (anti-BSA+BSA). For each group $n=6$.

$\mathrm{pg} / \mathrm{ml}$; anti-BSA + BSA) (Fig. 6), consistent with prior studies (13). Rats that received $0.5 \mathrm{ml}$ preimmune serum at the initiation of immune complex deposition (anti-BSA+BSA+preimmune) did not show any significant difference in the level of IL-1 $\beta$ in the BAL fluids $(18.0 \pm 5 \mathrm{pg} / \mathrm{ml})$ when compared with results in the anti-BSA + BSA group (Fig. 6). However, in rats

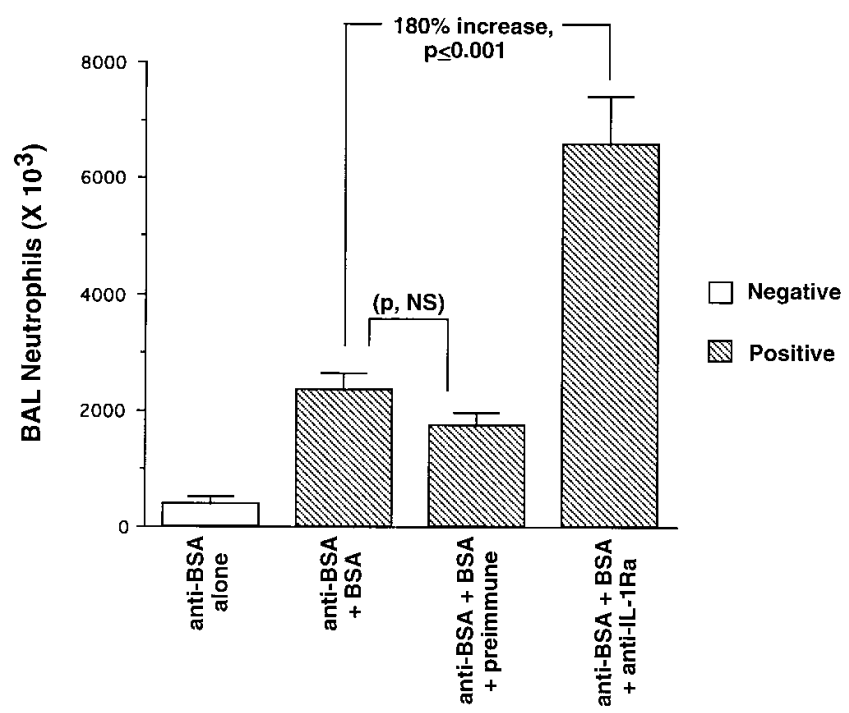

Figure 5. Effect of anti-IL-1Ra treatment on BAL neutrophil content $4 \mathrm{~h}$ after intrapulmonary deposition of IgG immune complexes. Animal groups are companions to those described in Fig. 4. Values are reported as BAL PMN counts $\times 10^{3}$. For each group $n=6$.

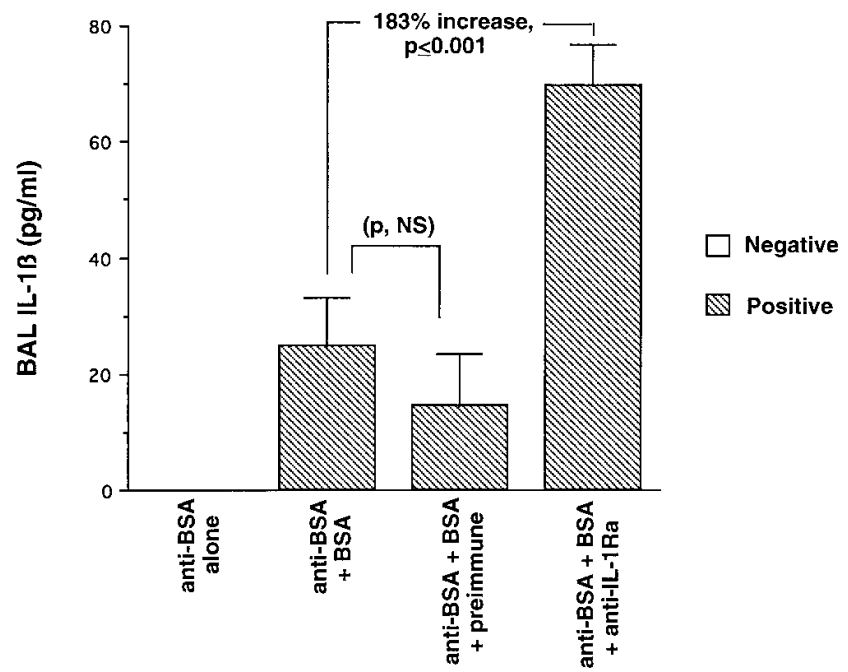

Figure 6. Effect of anti-IL-1Ra treatment on BAL IL-1 $\beta$ content in lung $4 \mathrm{~h}$ after intrapulmonary deposition of IgG immune complexes. Animal groups are companions to those described in Fig. 4. For each group $n=5$.

treated with antiserum to IL-1Ra at the commencement of injury (Fig. 6; anti-BSA+BSA+anti-IL-1Ra), there was a $183 \%$ increase $(P<0.001)$ in BAL IL-1 $\beta(69.8 \pm 16 \mathrm{pg} / \mathrm{ml})$ when compared with the anti-BSA + BSA group (Fig. 6), which correlated with the increase in BAL neutrophils (Fig. 5), suggesting that naturally expressed IL-1Ra negatively regulates in vivo production of IL-1 $\beta$.

Effect of anti-IL-1Ra on TNF- $\alpha$ content in BAL fluids. Levels of TNF- $\alpha$ in BAL fluids obtained $4 \mathrm{~h}$ after commencement of intrapulmonary deposition of IgG immune complexes were also determined. Anti-BSA alone rats had low levels of TNF- $\alpha(103 \pm 62 \mathrm{pg} / \mathrm{ml})$ in BAL fluids (Fig. 7). Injury initiated by IgG immune complex deposition (anti-BSA+BSA) resulted in a substantial increase in BAL fluid content of TNF- $\alpha$

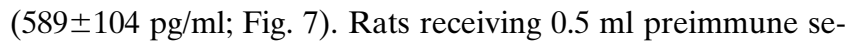
rum at the initiation of immune complex deposition (anti-BSA $+B S A+$ preimmune) did not show a significant change in the level of TNF- $\alpha$ in the BAL fluids $(547 \pm 121 \mathrm{pg} / \mathrm{ml})$ when compared with results obtained from the anti-BSA + BSA group (Fig. 7). Rats treated with antiserum to IL-1Ra at the commencement of injury (Fig. 7; anti-BSA+BSA+anti-IL-1Ra) showed no significant difference $(P=0.267)$ in BAL content of TNF- $\alpha(671 \pm 51 \mathrm{pg} / \mathrm{ml})$ when compared with the anti-BSA + BSA group (Fig. 7). Because we observed a trend toward increased TNF- $\alpha$ content in the animals treated with antiserum to IL-1Ra, the study was repeated in a companion set of animals ( $n=5$; data not shown). In this study, TNF- $\alpha$ content was $86 \pm 53 \mathrm{pg} / \mathrm{ml}$ in anti-BSA alone animals. TNF- $\alpha$ content in anti-BSA + BSA animals either untreated $(351 \pm 57 \mathrm{pg} / \mathrm{ml})$ or given preimmune serum $(436 \pm 156 \mathrm{pg} / \mathrm{ml})$ did not differ significantly $(P=0.33)$ from those treated with anti-IL-1Ra $(505 \pm 80 \mathrm{pg} / \mathrm{ml})$. Thus, in vivo blocking of IL-1Ra affected intrapulmonary production of IL- $1 \beta$ but not TNF- $\alpha$.

Regulation of $I L-1 \beta$ content in BAL fluids by $I L-10$. We have previously demonstrated that neutralization of intrinsic IL-10 also results in an augmentation of injury in this model by a mechanism due at least in part to increased TNF- $\alpha$ production (15). Because previous studies suggested that IL-1 $\beta$ pro- 


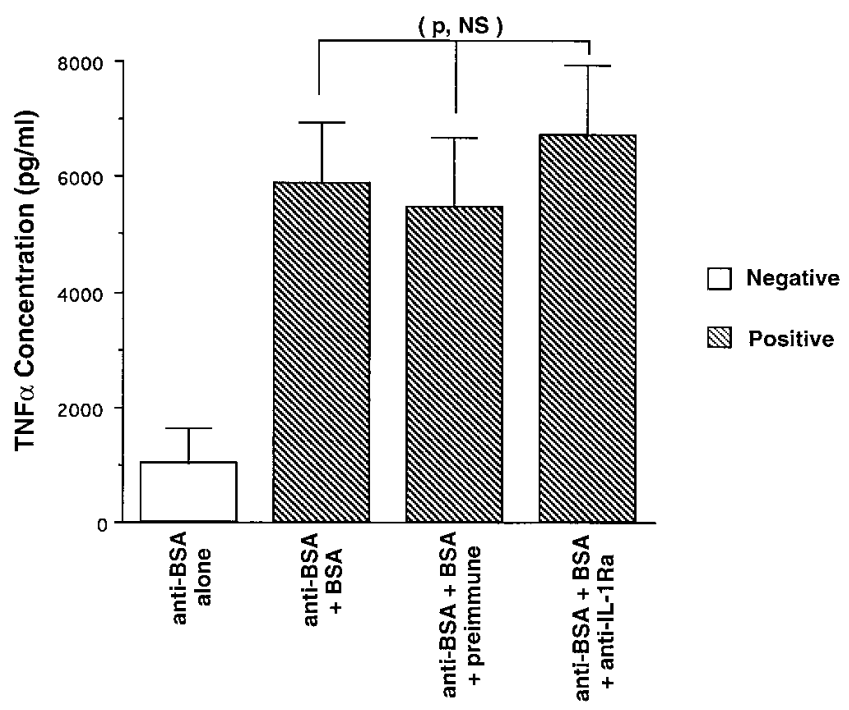

Figure 7. Effect of anti-IL-1Ra treatment on BAL TNF- $\alpha$ content $4 \mathrm{~h}$ after intrapulmonary deposition of $\mathrm{IgG}$ immune complexes. Animal groups are companions to those described in Fig. 4. For each group $n=5$.

duction is driven by TNF- $\alpha$, we sought to determine the effect of anti-IL-10 on levels of IL-1 $\beta$ in BAL fluids obtained $4 \mathrm{~h}$ after initiation of lung-inflammatory reactions. These determinations were performed on the samples previously analyzed for TNF- $\alpha$ content for which a $53 \%$ increase in TNF- $\alpha$ was observed (15). Anti-BSA alone animals had no IL-1 $\beta$ detectable in BAL fluids by this assay (Fig. 8). Intrapulmonary deposition of IgG immune complexes resulted in a significant increase in

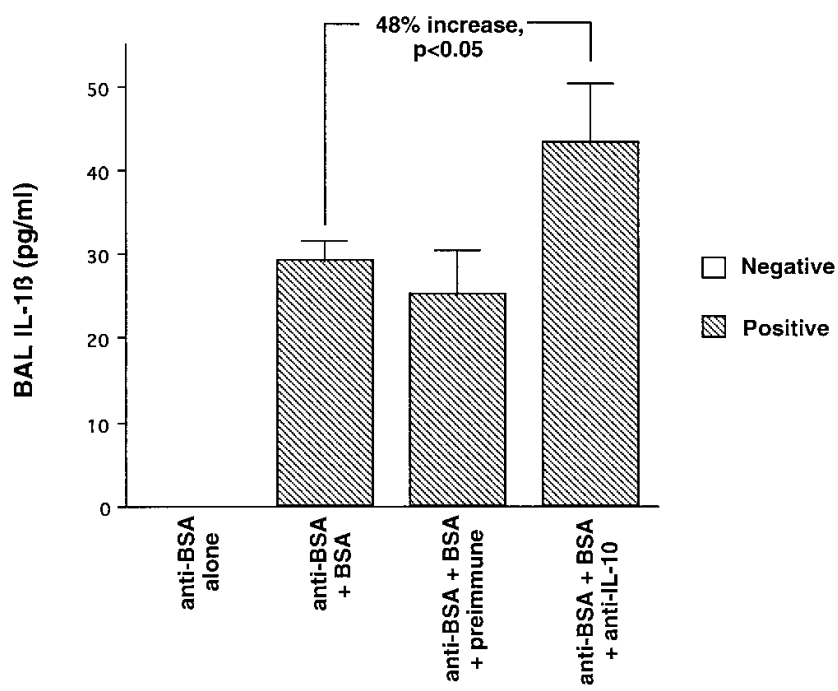

Figure 8. Effect of anti-IL-10 treatment on BAL IL-1 $\beta$ content in lung $4 \mathrm{~h}$ after intrapulmonary deposition of $\mathrm{IgG}$ immune complexes. Negative control animals designated anti-BSA alone (open bars) received anti-BSA intratracheally, with omission of the intravenous dose of BSA. The remaining groups underwent lung injury induced by IgG immune complex deposition (stippled bars) as described in Methods. Subsequently, rats received either preimmune serum (anti$B S A+B S A+$ preimmune) or anti-IL-10 serum (anti-BSA + BSA+ anti-IL-10) intravenously at time 0 , or were otherwise untreated (anti-BSA+BSA). For each group $n=5$.
IL-1 $\beta(29.2 \pm 4.6 \mathrm{pg} / \mathrm{ml}$; anti-BSA $+B S A)$ (Fig. 8). Rats receiving $0.5 \mathrm{ml}$ preimmune serum at the initiation of immune complex deposition (Fig. 8; anti-BSA+BSA+preimmune) did not show any significant difference in the level of IL-1 $\beta$ in the BAL fluids $(25.1 \pm 5.4 \mathrm{pg} / \mathrm{ml})$ when compared with results in the anti-BSA + BSA group. However, in animals treated with antiserum to IL-10 (anti-BSA $+B S A+$ anti-IL-10), there was a $48 \%$ increase $(P<0.05)$ in BAL IL-1 $\beta(43.2 \pm 7.8 \mathrm{pg} / \mathrm{ml})$ when compared with the anti-BSA + BSA group (Fig. 8). One provisional explanation for this finding may be that TNF- $\alpha$ is capable of driving production of IL- $1 \beta$ in this model of lung injury; however, this conclusion cannot be made on the basis of the data presented. In addition, whereas IL-10 regulates the in vivo production of both TNF- $\alpha$ and IL- $1 \beta$, the in vivo regulatory effects of IL-1Ra appear to be restricted to IL-1 $\beta$.

\section{Discussion}

These studies show that the IL-1Ra is upregulated (as defined by lung content of mRNA as well as by detection of IL-1Ra protein) in the model of acute lung injury after intrapulmonary deposition of $\mathrm{IgG}$ immune complexes. The neutralization of intrinsic IL-1Ra by administration of anti-IL-1Ra antibody leads to an augmentation of injury as measured by increased pulmonary vascular permeability and substantially increased numbers of recoverable BAL neutrophils. This augmentation appears to be directly correlated to increased levels of IL-1 $\beta$, whereas the TNF- $\alpha$ content of BAL fluids is unaffected.

The IL- 1 proteins, IL- $1 \alpha$ and IL- $1 \beta$, are implicated in numerous physiologic host responses to trauma, stress, and infection $(1,2)$. Many of the actions of IL-1 are proinflammatory and include the ability of IL- 1 to stimulate prostaglandin $E_{2}$ synthesis (21), to induce neutrophil accumulation (4), to cause fever, and to upregulate endothelial adhesion molecule expression. Given these divergent mechanisms of action, it seemed likely that IL-1 is regulated in vivo. Though there are several unidentified inhibitors of IL-1, one of the best characterized is IL-1Ra. A $22-25-\mathrm{kD}$ inhibitor of IL-1 bioactivity contained in the supernatant fluids of human monocytes adherent to IgG was first reported in 1985 (22) and was subsequently demonstrated to be a competitive inhibitor of binding to the IL-1 receptor (8). After these studies, this specific inhibitor of IL-1 bioactivity was cloned and functionally expressed $(9,10)$. An identical inhibitor was also identified from a human monomyelocytic cell line stimulated with PMA and GM-CSF (11). This protein inhibited biologic activity of IL-1 by principally binding to the $80-\mathrm{kD}$ IL-1 type I receptor with an affinity approximately equal to that of IL- $1 \alpha$ and IL-1 $\beta$, without initiating an IL-1-like response (23). Subsequently, this protein was demonstrated to have significant antiinflammatory activity when infused into animals $(24,25)$. IL-1Ra reduced mortality from endotoxin shock in rabbits (26) and mice (27). In human volunteers, IL-1Ra blocked the usual hypotension and leukopenia observed after endotoxin administration (28). That IL-1 plays a role in the $\mathrm{IgG}$ model of lung inflammation described above was determined by neutralization studies with an antiIL-1 $\beta$ antibody (13) and by the exogenous administration of human IL-1Ra (29). Since IL-1 $\beta$ produced in this model is likely to be regulated and since monocytes adherent to solidphase IgG showed increased IL-1Ra production in vitro (22), we sought to determine if IL-1Ra was intrinsically produced in vivo in the context of acute lung injury after $\mathrm{IgG}$ immune com- 
plex deposition, and to determine if IL-1Ra has regulatory effects in this model.

By the use of blocking antibody to IL-1Ra, the data suggest that IL-1Ra acts in vivo to downregulate the inflammatory response after intrapulmonary deposition of IgG immune complexes, as evidenced by the increase in pulmonary vascular permeability and increased BAL neutrophil counts. This is the first report of a role for intrinsic IL-1Ra in the context of acute lung injury; however, these findings are consistent with those of other in vivo inflammatory models. For example, intrinsic IL-1Ra has been shown to play a role in limiting the formation of granulomas after intrapulmonary challenge with Schistosoma mansoni eggs (30). A similar observation was made using a rabbit model of immune colitis in which the administration of neutralizing antibody against rabbit IL-1Ra increased mortality and prolonged intestinal inflammatory responses $(31,32)$.

The data provide further insights into regulation of the cytokine network in this acute lung injury model. In this model, IL-1Ra appears to principally regulate IL-1 concentration, since blocking of IL-1Ra with antibody led to a significant increase in IL-1 $\beta$ in BAL fluids from rats compared with positive controls in the absence of a significant change in TNF- $\alpha$ activity under the same experimental conditions. Though this finding differs from the in vitro observation that IL-1Ra inhibits TNF- $\alpha$ production by mononuclear phagocytes in response to endotoxin (33), it is consistent with the observation in vivo that IL-1Ra administration decreased plasma IL-1 $\beta$ and IL-6 levels in a baboon model of endotoxemia without having an effect on TNF- $\alpha$ plasma concentrations (34). Therefore, it appears in vivo that IL-1Ra is able to regulate IL- $1 \beta$ independently of any regulation of TNF- $\alpha$. Alternatively, it is possible that endogenous IL-1Ra production limits the influx of IL-1 $\beta-$ producing cells. For example, the administration of human IL$1 \mathrm{Ra}$ in this model of lung injury was associated with decreased myeloperoxidase content (29), a marker of neutrophil influx. In this case, the neutralization of intrinsic IL-1Ra would result in increased influx of IL- $1 \beta$-producing cells and increased levels of IL- $1 \beta$ in BAL fluids.

This mechanism of cytokine regulation differs from that of another autoregulatory cytokine, IL-10. We have previously shown that extrinsically administered IL-10 reduces TNF- $\alpha$ levels in BAL fluids in the IgG model of immune complexinduced lung injury (35), whereas neutralization of intrinsic IL-10 results in an augmentation of injury in this model of lung injury in association with increased BAL fluid content of TNF- $\alpha$ (15). The current studies demonstrate that the increase in TNF- $\alpha$ as a result of IL-10 neutralization is accompanied by a similar increase in IL-1 $\beta$. This finding is consistent with previous in vivo studies that suggest a temporal relationship between TNF- $\alpha$, IL-1 $\beta$, and IL-1Ra expression. In experimental endotoxemia in humans, peak TNF- $\alpha$ levels are observed at 60-90 min, with return to pretreatment levels by the time IL$1 \beta$ levels are maximal $(36,37)$; peak levels of IL- $1 \beta$ occur after $3-4 \mathrm{~h}$, then fall off rapidly $(28,38)$. In the same individuals, peak expression of IL-1Ra is observed after $4 \mathrm{~h}(28,38)$ and can exceed the concentration of IL- $1 \beta$ by as much as 100 -fold (28). In the model of IgG immune complex alveolitis, this temporal relationship appears to be similar in that peak protein expression of IL-1Ra appears to occur later $(6 \mathrm{~h})$ than that for IL- $1 \beta$ and TNF- $\alpha$.

In the lung injury model described in this report, IL-1Ra was produced by at least two cellular sources. While it is clear that alveolar macrophages produce IL-1Ra constitutively in vitro, there are conflicting reports as to the ability of these mature cell types to increase expression of IL-1Ra in response to inflammatory stimuli such as LPS or TNF- $\alpha$ (39-41). Despite these observations, alveolar macrophages stimulated in vivo with IgG immune complexes were a significant source of IL$1 \mathrm{Ra}$ production as identified by immunofluorescent staining. The neutrophil has been identified as a second source of IL$1 \mathrm{Ra}$ production both in vitro $(42,43)$ and in vivo in the setting of rheumatoid arthritis (44). Immunofluorescent staining suggested that the neutrophil serves as a second source of IL-1Ra production in this model of lung injury. Two molecules that have been demonstrated to augment production of IL-1Ra by human monocytes and/or neutrophils are IL-4 $(12,41,45)$ and IL-10 $(46,47)$. Exogenously administered IL-4 and IL-10 both resulted in decreased injury in this $\mathrm{IgG}$ immune complex model (35). While the in vitro data suggest that a potential mechanism for this protection is induction of IL-1Ra, this hypothesis remains to be proven. Additional sources of IL-1Ra include epithelial cells, including keratinocytes from which an intracellular form of IL-1Ra has been cloned (48), although whether this form of IL-1Ra is secreted and plays a role in regulation of inflammatory responses remains to be determined.

These data have important implications for patients with acute lung injury since there are accumulating data that link increased production of IL- $1 \beta$ with the development of acute respiratory distress syndrome (49-52). Patients with acute respiratory distress syndrome have increased levels of IL- $1 \beta$ in BAL fluids and increased production of IL- $1 \beta$ by alveolar macrophages (49). Since IL-1Ra appears to serve as an important regulator of this cytokine, it may be important to determine the level of expression of IL-1Ra compared with IL-1 $\beta$ in the context of acute lung injury.

In conclusion, these studies indicate that endogenously produced IL-1Ra contributes to limiting the intensity of the inflammatory response after intrapulmonary deposition of IgG immune complexes.

\section{Acknowledgments}

The authors thank Ms. Robin Kunkel for her assistance in the preparation of the figures used in this manuscript and to Ms. Beverly Schumann for her assistance in the preparation of the manuscript.

This work was supported by National Institutes of Health grant HL-31963 and GM-29507. T.P. Shanley is a National Institutes of Health Fellow of the Pediatric Scientist Training Program.

\section{References}

1. Dinarello, C.A. 1991. Interleukin-1 and interleukin-1 antagonism. Blood. 77:1627-1652.

2. Dinarello, C.A. 1994. The interleukin-1 family: 10 years of discovery. FASEB J. 8:1314-1325.

3. Arfors, K.-E., C. Lundberg, L. Lindbom, K. Lundberg, P.G. Beatty, and J.M. Harlan. 1987. A monoclonal antibody to the membrane glycoprotein complex CD18 inhibits polymorphonuclear leukocyte accumulation and plasma leakage in vivo. Blood. 69:338-340.

4. Ulich, T.R., Y. Songmei, K. Guo, J. del Castillo, S.P. Eisenberg, and R.C. Thompson. 1991. The intratracheal administration of endotoxin and cytokines. III. The interleukin-1 (IL-1) receptor antagonist inhibits endotoxin- and IL-1induced acute inflammation. Am. J. Pathol. 138:521-524.

5. Smith, J., W. Urba, R. Steis, J. Janik, B. Fenton, W. Sharfman, K. Conlon, M. Sznol, S. Creekmore, N. Wells, et al. 1990. Interleukin-1 alpha: results of a phase I toxicity and immunomodulatory trial. Proc. Annu. Meet. Am. Soc. Clin. Oncol. 9:A717.

6. Larrick, J.W. 1989. Native interleukin 1 inhibitors. Immunol. Today. 10: 
$61-66$

7. Muchmore, A.V., and J.M. Decker. 1986. Uromodulin: an immunosuppressive 85-kilodalton glycoprotein isolated from human pregnancy urine is a high affinity ligand for recombinant interleukin-1 $\alpha$. J. Biol. Chem. 261:1340413407.

8. Seckinger, P., J.W. Lowenthal, K. Williamson, J.-M. Dayer, and H.R. MacDonald. 1987. A urine inhibitor of interleukin 1 activity that blocks ligand binding. J. Immunol. 139:1546-1549.

9. Eisenberg, S.P., R.J. Evans, W.P. Arend, E. Verderber, M.J. Brewer, C.H. Hannum, and R.C. Thompson. 1990. Primary structure and functional expression from complimentary DNA of a human interleukin-1 receptor antagonist. Nature (Lond.). 343:341-346.

10. Hannum, C.H., C.J. Wilcox, W.P. Arend, F.G. Joslin, D.J. Dripps, P.L. Heimdal, L.G. Armes, A. Sommer, S.P. Eisenberg, and R.C. Thompson. 1990. Interleukin-1 receptor antagonist activity of a human interleukin-1 inhibitor. Nature (Lond.). 343:336-340.

11. Carter, D.B., M.R. Deibel, C.J. Dunn, C.C. Tomich, A.L. Laborde, J.L. Slightom, A.E. Berger, M.J. Bienkowski, F.F. Sun, R.N. McEwan, et al. 1990. Purification, cloning, expression and biologic characterization of an interleukin1 receptor antagonist protein. Nature (Lond.). 344:633-638.

12. Rochemonteix, B.G., L.P. Nicod, R. Chicheportiche, S. Lacraz, C. Baumberger, and J.-M. Dayer. 1993. Regulation of interleukin-1ra, interleukin$1 \alpha$, and interleukin- $1 \beta$ production by human alveolar macrophages with phorbol myristate acetate, lipopolysaccharide, and interleukin-4. Am. J. Respir. Cell Mol. Biol. 8:160-168.

13. Warren, J.S. 1991. Intrapulmonary interleukin-1 mediates acute immune complex alveolitis in the rat. Biochem. Biophys. Res. Commun. 175:604610.

14. Arend, W.P., F.G. Joslin, R.C. Thompson, and C.H. Hannum. 1989. An IL-1 inhibitor from human monocytes. Production and characterization of biologic properties. J. Immunol. 143:31851-31858.

15. Shanley, T.P., H. Schmal, H.P. Friedl, M.L. Jones, and P.A. Ward. 1995. Regulatory effects of intrinsic IL-10 in IgG immune complex-induced lung injury. J. Immunol. 154:3454-3460.

16. Mulligan, M.S., J.M. Hevel, M.A. Marletta, and P.A. Ward. 1991. Tissue injury caused by deposition of immune complexes is L-arginine dependent. Proc. Natl. Acad. Sci. USA. 88:6338-6342.

17. Eisenberg, S.P., M.T. Brewer, E. Verderber, P. Heimdal, B.J. Brandhuber, and R.C. Thompson. 1991. Interleukin-1 receptor antagonist is a member of the interleukin gene family: evolution of a cytokine control mechanism. Proc. Natl. Acad. Sci. USA. 88:5232-5236.

18. Chirgwin, J.M., A.E. Pryzbyla, R.J. MacDonald, and W.J. Rutter. 1979. Isolation of biologically active ribonucleic acid from sources enriched in ribonuclease. Biochemistry. 18:5294-5299.

19. Laemmli, U.K. 1970. Cleavage of structural proteins during the assembly of the bacteriophage T4. Nature (Lond.). 227:680-685.

20. Warren, J.S., K.R. Yabroff, D.G. Remick, S.L. Kunkel, S.W. Chensue, R.G. Kunkel, K.J. Johnson, and P.A. Ward. 1989. Tumor necrosis factor participates in the pathogenesis of acute immune complex alveolitis in the rat. J. Clin. Invest. 84:1873-1882.

21. Gubler, U., A.O. Chua, A.S. Stern, C.P. Hellmann, M.P. Vitek, T.M. DeChiara, W.R. Benjamin, K.J. Collier, M. Dukovich, P.C. Familletti, et al. 1986. Recombinant human interleukin-1 $\alpha$ : purification and biological characterization. J. Immunol. 136:2492-2497.

22. Arend, W.P., F.G. Joslin, and R.J. Massoni. 1985. Effects of immune complexes on production by human monocytes of interleukin-1 or interleukin-1 inhibitor(s). J. Clin. Invest. 78:1120-1124.

23. Dripps, D.J., B.J. Brandhuler, R.C. Thompson, and S.P. Eisenberg. 1991. Interleukin-1 (IL-1) receptor antagonist binds to the 80-kDa IL-1 receptor but does not initiate signal transduction. J. Biol. Chem. 266:10331-10336.

24. Dinarello, C.A., and R.C. Thompson. 1991. Blocking IL-1: interleukin 1 receptor antagonist in vivo and in vitro. Immunol. Today. 12:404-410.

25. Arend, W.P. 1991. Interleukin 1 receptor antagonist. A new member of the interleukin 1 family. J. Clin. Invest. 88:1445-1451.

26. Ohlsson, K., P. Bjork, M. Bergenfeldt, R. Hegeman, and R.C. Thompson. 1990. Interleukin-1 receptor antagonist reduces mortality from endotoxin shock. Nature (Lond.). 348:550-552.

27. Alexander, H.R., G.M. Doherty, C.M. Buresh, D.J. Venzon, and J.A. Norton. 1991. A recombinant human receptor antagonist to interleukin-1 improves survival after lethal endotoxemia in mice. J. Exp. Med. 173:1029-1032.

28. Fischer, E., K.J. Van Zee, M.A. Marano, C.S. Rock, J.S. Kenney, D.D. Poutsiaka, C.A. Dinarello, S.F. Lowry, and L.L. Moldawer. 1992. Interleukin-1 receptor antagonist circulates in experimental inflammation and in human disease. Blood. 79:2196-2200.

29. Mulligan, M.S., and P.A. Ward. 1992. Immune complex-induced lung and dermal vascular injury: differing requirements for TNF- $\alpha$ and IL-1. J. Immunol. 149:331-339.

30. Chensue, S.W., M. Bienkowski, T.E. Eessalu, K.S. Warmington, S.D. Hershey, N.W. Lukacs, and S.L. Kunkel. 1993. Endogenous IL-1 receptor antagonist protein (IL-1Ra) regulates schistosome egg granuloma formation and the regional lymphoid response. J. Immunol. 151:3654-3662.
31. Cominelli, F., C.C. Nast, A. Duchini, and M. Lee. 1992. Recombinant interleukin-1 receptor antagonist blocks the activity of endogenous interleukin1 in rabbit immune colitis. Gastroenterology. 103:65-71.

32. Ferretti, M., V. Casini-Raggi, T.T. Pizarro, S.P. Eisenberg, C.C. Nast, and F. Cominelli. 1994. Neutralization of endogenous IL-1 receptor antagonist exacerbates and prolongs inflammation in rabbit immune colitis. J. Clin. Invest. 94:449-453.

33. Marsh, C.B., S.A. Moore, H.A. Pope, and M.D. Wewers. 1994. Cytokine-induced interleukin-1 receptor antagonist release in mononuclear phagocytes. Am. J. Physiol. 267:L39-L45.

34. Fischer, E., M.A. Marano, K.J. van Zee, C.S. Rook, A.S. Hawes, W.A Thompson, L. DeForge, J.S. Kenney, D.G. Remick, D.C. Bloedow, et al. 1992. Interleukin-1 receptor blockade improves survival and hemodynamic performance in Escherichia coli septic shock, but fails to alter host responses to sublethal endotoxemia. J. Clin. Invest. 89:1551-1557.

35. Mulligan, M.S., M. Howard, M.L. Jones, and P.A. Ward. 1993. Protective effects of IL-4 and IL-10 against immune complex-induced lung injury. $J$. Immunol. 151:5666-5674.

36. Cannon, J.G., R.G. Tompkins, J.A. Gelfand, H.R. Michie, G.G. Stanford, J.W.M. van der Meer, S. Endres, G. Lonnemann, J. Corsetti, B. Chernow et al. 1990. Circulating interleukin-1 and tumor necrosis factor in septic shock and experimental endotoxin fever. J. Infect. Dis. 161:79-84.

37. Michie, H.R., K.R. Monague, D.R. Spriggs, A. Revhaug, S. O’Dwyer, C.A. Dinarello, A. Cerami, S.M. Wolff, and D.W. Wilmore. 1988. Detection of circulating tumor necrosis factor after endotoxin administration. N. Engl. J. Med. 318:1481-1486.

38. Hesse, D.G., K.J. Tracey, Y. Fong, K.R. Manogue, M.A. Palladino, A Cerami, G.T. Shives, and S.F. Lowry. 1988. Cytokine appearances in human endotoxemia and primate bacteremia. Surg. Gynecol. \& Obstet. 166:147-153.

39. Kline, J.N., M.M. Monick, and G.W. Hunninghake. 1992. IL-1 receptor antagonist release is regulated differently in human alveolar macrophages than in monocytes. J. Appl. Physiol. 73:1686-1602.

40. Marsh, C.B., and M. Wewers. 1994. Cytokine-induced interleukin-1 receptor antagonist release in mononuclear phagocytes. Am. J. Respir. Cell Mol. Biol. 10:521-525.

41. Moore, S.A., R.M. Strieter, M.W. Rolfe, T.J. Standiford, M.D. Burdick, and S.L. Kunkel. 1992. Expression and regulation of human alveolar macrophage-derived interleukin-1 receptor antagonist. Am. J. Respir. Cell Mol. Biol. 6:569-575.

42. Malyak, M., M.F. Smith, A.A. Abel, and W.P. Arend. 1994. Peripheral blood neutrophil production of interleukin-1 receptor antagonist and interleukin-1ß. J. Clin. Invest. 14:20-30.

43. Chang, D.M. 1995. Cellular signals for the induction of human interleukin-1 receptor antagonist. Clin. Immunol. Immunopathol. 74:23-30.

44. Malyak, M., R.E. Swaney, and W.P. Arend. 1993. Levels of synovial fluid interleukin-1 receptor antagonist in rheumatoid arthritis and other arthropathies: potential contribution from synovial fluid neutrophils. Arthritis \& Rheum. 36:781-789.

45. Sone, S., E. Orino, S. Yano, Y. Nishioka, T. Haku, A. Nii, and T. Ogura 1994. Production of IL-1 and its receptor antagonist is regulated differently by IFN-gamma and IL-4 in human monocytes and alveolar macrophages. Eur. Respir. J. 7:657-663.

46. Cassatella, M.A., L. Meda, S. Gasperini, F. Calzetti, and S. Bonora. 1994. Interleukin-10 (IL-10) upregulates IL-1 receptor antagonist production from lipopolysaccharide-stimulated human polymorphonuclear leukocytes by delaying mRNA degradation. J. Exp. Med. 179:1695-1696.

47. Jenkins, J.K., M. Malyak, and W.P. Arend. 1994. The effects of interleukin-10 on interleukin-1 receptor antagonist and interleukin-1 $\beta$ production in human monocytes and neutrophils. Lymphokine Cytokine Res. 13:47-54.

48. Haskill, S., G. Martin, L. Van Le, J. Morris, A. Peace, C.F. Bigler, G.J. Jaffe, C. Hammerberg, S.A. Sporn, S. Fong, W.P. Arend, and P. Ralph. 1991 cDNA cloning of an intracellular form of the human interleukin 1 receptor antagonist associated with epithelium. Proc. Natl. Acad. Sci. USA. 88:3681-3685.

49. Suter, P.M., S. Suter, E. Girardin, P. Roux-Lombard, G.E. Grau, and J.-M. Dayer. 1991. High bronchoalveolar levels of tumor necrosis factor and its inhibitors, interleukin-1, interferon and elastase, in patients with adult respiratory distress syndrome after trauma, shock, or sepsis. Am. Rev. Respir. Dis. 145 $1016-1022$.

50. Siler, T.M., J.E. Swierkosz, T.M. Hyers, A.A. Fowler, and R.O. Webster. 1989. Immunoreactive interleukin-1 in bronchoalveolar lavage fluid of high-risk patients and patients with the adult respiratory distress syndrome. Exp. Lung Res. 15:881-894.

51. Jacobs, R.F., D.R. Tabor, A.W. Burks, and G.D. Campbell. 1989. Elevated interleukin-1 release by human alveolar macrophages during the adult respiratory distress syndrome. Am. Rev. Respir. Dis. 140:1686-1692.

52. Roumen, R.M., T. Hendriks, J. van der Ven-Jongekrig, G.A.P. Nieuwenhuijzen, R.W. Sauerwein, J.W.M. van der Meer, and R.J.A. Goris. 1993 Cytokine patterns in patients after major vascular surgery, hemorrhagic shock and severe blunt trauma. Relation with subsequent adult respiratory distress syndrome and multiple organ failure. Ann. Surg. 218:769-776. 